\title{
TEMPO, MIIDIA E PROCESSOS SOCIOPOLÍTICOS NO BRASIL DO SÉCULO XXI: PERSPECTIVAS SOCIOSSEMIÓTICAS
}

TIME, MEDIA AND SOCIO-POLITICAL PROCESSES IN XXI CENTURY BRAZIL: SOCIO-SEMIOTIC PERSPECTIVES

TEMPO, MEDIA E PROCESOS SOCIOPOLITICOS EN EL BRASIL DEL SIGLO XXI: PERSPECTIVAS SOCIOSSEMIÓTICAS

Paolo Demuru'

RESUMO: A partir de uma releitura dos conceitos de acidente de Eric Landowski e de explosão de Jurij M. Lotman, este artigo analisa as correlações entre o tempo mediático e o tempo sociopolítico do processo que levou das jornadas de junho de 2013 ao impeachment de Dilma Rousseff. As hipóteses defendidas são: (i) junho de 2013 constitui um evento acidental/explosivo que projeta o Brasil em um presente atemporal amorfo e imprevisível, o qual se estende, ao menos, até o impedimento da ex-presidente; (ii) tal regime temporal define-se por um elevado grau de indeterminação semântica e por um elevado grau de carga estésica, isto é, de tensões e forças sensíveis que se alastram no corpo social; e (iii) as mídias sociais cumprem, nesse percurso, um papel catalítico: são elas que engendram a indeterminação e a carga estésica que dão corpo ao novo regime temporal. Almejase, assim, contribuir à construção de quadros teóricos capazes de dar conta da natureza semiótica do tempo no campo da Comunicação.

Palavras-chave: Temporalidade. Processos sociopolíticos. Sociossemiótica.

ORCID: 0000-0003-1559-9530 E-mail: paolodemuru@gmail.com 
ABSTRACT: The aim of this paper is to tackle the links between the mediatic and socio-political time of the process that led from the 2013 protests to the impeachment of the former Brazilian president Dilma Rousseff. In order to do that, a review of Landowski's concept of accident and Lotman's notion of explosion is done. Our hypotheses are: (i) June of 2013 is an accidental/explosive event that projects Brazil into an amorphous and unpredictable atemporal present, which extends, at least, to the former president's impeachment; (ii) this temporal regime is defined by a high degree of semantic indetermination and by a high degree of aesthetic load, that is, of sensitive tensions and forces that spread quickly in the social body; (iii) social media displays, in this process, a catalytic role, generating both the indetermination and the aesthetic load that feature the new temporal regime. It is hoped, therefore, to contribute to the construction of theoretical frameworks capable of accounting for the semiotic nature of time in the field of communication studies.

Palavras-chave: Temporality. Socio-political processes. Sociossemiotics.

RESUMEN: A partir de una relectura de los conceptos de accidente de Eric Landowski e de explosión de Jurij M. Lotman, este artículo analiza las correlaciones entre el tiempo mediático y el tiempo sociopolítico del proceso que llevó de las jornadas de junio de 2013 al impeachment de Dilma Rousseff. Las hipótesis defendidas son: (i) junio de 2013 constituye un evento accidental/explosivo que catapulta a Brasil en un presente atemporal amorfo e imprevisible, el cual se extiende, al menos, hasta el impedimento de la ex presidenta; (ii) tal régimen temporal se define por un alto grado de indeterminación semántica y por un elevado grado de carga estética, es decir, de tensiones y fuerzas sensibles que se extienden en el cuerpo social; (iii) los medios sociales cumplen, en este recorrido, un papel catalítico: son ellas las que engendran la indeterminación y la carga estética que dan cuerpo al nuevo régimen temporal. Se pretende, así, contribuir a la construcción de cuadros teóricos capaces de dar cuenta de la naturaleza semiótica del tiempo en el campo de la comunicación.

Palabras-clave: Temporalidad. Procesos sociopolíticos. Sociossemiótica. 


\section{Introdução}

"Talvez a emoção do tempo seja precisamente o que é o tempo para nós". (Carlo Rovelli)

Com base em um diálogo entre a sociossemiótica de Eric Landowski (2014) e a semiótica da cultura de Jurij M. Lotman $(1995 ; 2009)$, proponho explorar, neste artigo, as correlações entre as temporalidades específicas do discurso mediático e a temporalidade geral do processo sociopolítico que levou, entre junho de 2013 e agosto de 2016, ao impeachment da ex-presidente do Brasil Dilma Rousseff.

Como apontam estudiosos de diversas extrações disciplinares, tal trajetória tem o seu ponto de partida naquelas que são hoje conhecidas como as "Jornadas de Junho de 2013" (NOBRE, 2013; BUCCl, 2016; SINGER, 2018). Convocados via Twitter e Facebook nos primeiros dias de junho pelo Movimento Passe Livre, os protestos possuíam, inicialmente, um objetivo preciso: revogar o aumento da tarifa do transporte público aprovado pelos governos estaduais e municipais em São Paulo, Rio de Janeiro e outras capitais. Contudo, após a primeira semana, o leque das reivindicações torna-se - quantitativa e qualitativamente - mais amplo e nebuloso: não é pelos vintes centavos, o gigante acordou, muda Brasil, mais saúde, etc. Nas palavras de André Singer, "os protestos adquiriram tal dimensão que parecia estar ocorrendo algo nas entranhas da sociedade, algo que poderia sair do controle. O problema é que não ficou claro que algo era esse" (SINGER, 2018, p. 102, grifo do autor).

Se, por um lado, essa virada semântica proporciona uma dilatação do campo discursivo das manifestações, pelo outro favorece um deslocamento de seu campo de mira. Não mais restritos à esfera das prefeituras e dos estados, os protestos dirigem-se agora para o país como um todo (SOUZA, 2016; SINGER, 2018). Além dos slogans acima citados, o signo mais nítido de tal reviravolta é a irrupção de bandeiras verde-amarelas nas ruas, nas redes e na mídia impressa e televisiva. "Como procurei mostrar em outras ocasiões, essas últimas contribuem a alimentar tanto a nevoeiro de significados quanto a projeção federal das jornadas, traçando o perfil de um Brasil abalado, cujo futuro estaria cada vez mais incerto (SCHWARZ, 2013)".

Após o dia 13 de junho de 2013, a então presidente Dilma Rousseff começa a se tornar o alvo da indignação surgidas nas ruas e nas redes. Em 15 de junho, em ocasião da abertura a Copa das Confederações, ela é vaiada pelo público do estádio Mané Garrincha, em Brasília (ALENCASTRO, 2013). No entanto, é 
nos anos seguintes, e precisamente após a sua reeleição em 2014, que Dilma e seu governo são apontados como os principais responsáveis pela suposta crise social e política da nação. Com as manifestações de 2015, convocadas pelo Movimento Brasil Livre (MBL), a hipótese do impeachment de Rousseff começa a ganhar corpo, culminando, em 31 de agosto de 2016, na deposição da presidente. No entanto, os valores que deveriam definir o novo Brasil permanecem, assim como em 2013, ambíguos.

Ora, se há um consenso, tanto no campo da comunicação quanto no campo das ciências sociais, em definir as jornadas de junho de 2013 como um abalo, uma quebra, uma ruptura que marca o começo do fim da era Lula (NOBRE, 2013; SOUZA, 2016; BUCCI, 2016; SINGER, 2018), pouco se discutiu e pouco se discute, ainda, sobre as dimensões temporais de tal processo, bem como sobre o papel da mídia em configurar e reconfigurar o seu devir.

O que define a temporalidade deste movimento sociopolítico? Quais seriam os seus traços distintivos? Existem, nele, tempos distintos? E, no caso, como eles se entrelaçam? Ainda: como a mídia contribui ou não contribuiu a moldá-lo e direcioná-lo? Quais são as diferenças entre o tempo das novas e das velhas mídias? Como eles se sobrepõem e se articulam? E qual é o efeito de sentido dessa articulação?

O meu objetivo é procurar preencher essa lacuna. Para tanto, partirei de uma releitura cruzada dos conceitos de acidente de Landowski (2014) e explosão de Jurij M. Lotman (1995; 2009), tecendo, quando oportuno, paralelos com outras abordagens do tempo elaboradas no campo das Ciências Sociais (HARTOG, 2015) e da Comunicação (CASTELLS, 2005; BARBOSA, 2017). Parece-me, pois, que os dois conceitos se complementam reciprocamente.

Tanto o acidente landowskiano quanto a explosão lotmaniana designam uma quebra na evolução gradual da história que abre para uma fase imprevisível, marcada por um alto grau de indeterminação semântica. Todavia, eles apresentam nuances que os distinguem um do outro. Para Landowski a indeterminação é negativa: o acidente é um acontecimento marcado pelo não sentido (LANDOWSKI, 2014, p. 71-80). Ao contrário, para Lotman a indeterminação é positiva: a explosão gera sempre um superávit semântico, sentido em excesso (LOTMAN, 1995; 2009). Entretanto, como defendo aqui, os dois podem ser considerados como as duas faces da mesma moeda.

Ainda: enquanto a explosão prevê a possibilidade de pensar a ruptura do continuum histórico sociocultural não apenas como um momento pontual, mas também enquanto um processo durativo, o acidente landowskiano, na releitura 
que proponho, aponta para a problemática da intensidade estésica do acontecimento, isto é, de sua dimensão sensível. Como veremos, trata-se de níveis de conceptualização teórico-metodológica que merecem uma abordagem conjunta.

Com base nesses pressupostos, as hipóteses que defendo são:

a) as jornadas de junho de 2013 constituem um acontecimento acidental/explosivo que faz colapsar o sistema de crenças e valores do lulismo - "o ressurgimento, no horizonte, de um país com algum futuro" (Nobre, 2013, não paginado), de um País menos desigual e mais desenvolvido (SCHWARZ, 2013; SINGER, 2018; SOUZA, 2016; BUCCl, 2016) - dando vida a um momento histórico imprevisível, o qual se estende até o impeachment de Dilma Rousseff e, pode-se presumir, às eleições presidenciais de 2018, embora não haja espaço para abordar, aqui, esta segunda fase do processo;

b) o regime temporal ao qual dá origem essa explosão distingue-se pela valorização paroxística da imediatez e pela alternância serializada de acontecimentos pontuais em relação entre si - um regime que, parafraseando Hartog, poder-se-ia definir "hiperpresentista" (HARTOG, 2015, p. XV);

c) os traços distintivos que definem esse regime temporal são: (i) um elevado grau de indeterminação semântica; e (ii) um elevado grau de "carga estésica", entendida como o borbulhar de tensões e forças sensíveis que emergem das interações sociais em um dado momento histórico e um dado contesto sociocultural. Mais do que isso: são exatamente a vagueza e a carga estésica que produzem o regime hiperpresentista, que fazem com que ele aconteça e se delineie enquanto tal;

d) as mídias digitais e, em particular, Twitter e Facebook cumprem, no percurso que vai das jornadas de junho de 2013 ao impeachment de Roussef, um papel catalítico: são elas que engendram a indeterminação e a carga estésica que dão corpo à explosão e ao regime hiperpresentista que a caracteriza;

e) o discurso da mídia impressa e televisiva dilata a temporalidade das redes, estendendo a explosão ao longo dos meses e dos anos sucessivos a junho de 2013 e contribuindo a confinar a sociedade e a política brasileira em um presente atemporal imprevisível.

Almeja-se, desta forma, contribuir não apenas à compreensão dos processos sociopolíticos em ato, no Brasil, na segunda década do século XXI, como também à construção de quadros teóricos capazes de dar conta da natureza sociossemiótico-discursiva do tempo no campo dos estudos comunicacionais.

\section{$\mathrm{O}$ acidente: relendo Eric Landowski}

Desenvolvendo a gramática narrativa de Greimas (GREIMAS; COURTÉS, 2008, p. 328), Landowski elabora em As interações sensíveis um modelo que visa dar conta dos regimes de sentido e interação que norteiam a existência humana (LANDOWSKI, 2014). Quatro são os regimes identificados por Landowski: programação, manipulação, ajustamento e acidente, que Landowski dispõe ao longo 
de um quadrado semiótico elíptico, o qual prevê a possibilidade de múltiplas articulações e saltos entre uma posição e outra.

Na programação, os sujeitos seguem com regularidade percursos narrativos regidos por princípios de causalidades físicas ou coerções sociais. É o reino da rotina e dos hábitos, no qual, como já havia apontado Greimas em Da Imperfeição (2002), tende-se à insignificância e à usura do sentido. $\mathrm{Na}$ manipulação interage-se conforme uma intencionalidade de tipo estratégico: um destinador leva um destinatário a querer ou a dever fazer alguma coisa, ou seja, a engajar-se em um determinado programa narrativo que prevê a aquisição de determinadas competências modais: poder-fazer, saber-fazer etc. No ajustamento não existem roteiros pré-programados ou estratégias definidas: os sujeitos constroem, a partir de um sentir comum e com foco em suas competências estésicas, uma relação que pode resultar, diz Landowski (2014, p. 54), em algum tipo de realização mútua. No acidente interage-se sob a égide do alea. É o regime da insensatez, no qual o acaso irrompe em sua forma mais pura, como no caso de tsunami, raios, terremotos ou mesmo de imprevistos felizes, de golpes de sortes inesperados (LANDOWSKI, 2014, p. 71).

Figura 1 - $O$ quadrado dos Regimes de Interação e Sentido de Eric Landowski

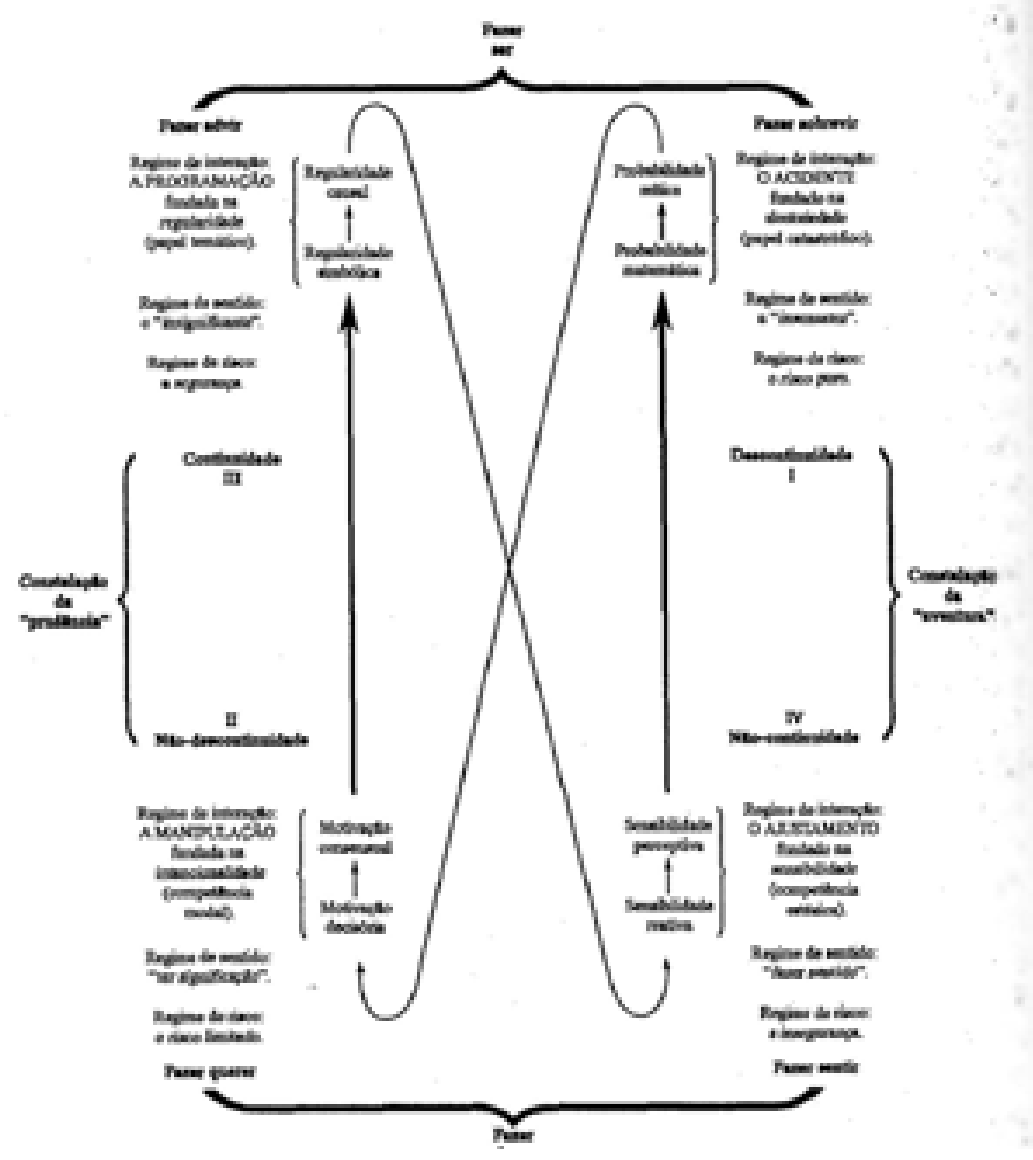


Fonte: Reprodução de Landowski (2014).

Porém, o que me interessa debater não é a lógica geral do modelo landowskiano, mas sim as suas dimensões temporais específicas e, sobretudo, aquelas do regime do acidente.

Como mostra a disposição dos regimes no quadrado (Figura 1), programação, acidente, manipulação e ajustamento ocupam, cada um, uma posição ao longo do percurso definido pelo desdobramento lógico semântico da categoria continuidade-descontinuidade: enquanto a programação é um processo contínuo, o acidente é um processo descontínuo; enquanto a manipulação é uma interação não descontínua, o ajustamento é uma interação não contínua.

Parece existir, portanto, uma configuração aspectual própria de cada regime. Conforme Greimas e Courtés (2008, p. 39-40), o aspecto é o ponto de vista sobre a ação. Enquanto o tempo é uma categoria que situa a ação em relação ao momento da enunciação, isto é, ao quando, o aspecto define o como a ação se dá, o ritmo através da qual ela se desenvolve. Uma ação pode ser descrita, assim, como acabada ou inacabada, sendo possíveis ressaltar aspectos diferentes de seu processo: a pontualidade, que ressalta a sua unicidade; a duratividade, que evidencia o seu estender-se no tempo; a iteratividade, que foca o seu repetir-se constante e regular; a incoatividade, que aponta para a sua dimensão inicial; a terminatividade, que marca o seu fim. Voltando aos regimes, pode-se dizer, por exemplo, que a programação é marcada por traços de duratividade e iteratividade, enquanto o acidente configura-se, aparentemente, como um evento pontual (GREIMAS; COURTÉS, 2008, p. 39-40).

A questão é complexa e merece ser abordada com cuidado. Quais seriam as configurações aspectuais, isto é, as marcas temporais próprias da manipulação e do ajustamento? Quais figuras e sequências rítmicas seriam mais adequadas para descrevê-los? Existe uma alternância e uma recursividade rítmico-temporal interna a cada regime? Deixo a busca por respostas a futuras investigações. Em consonância com os escopos do presente artigo, detenho-me, a seguir, na releitura dos elos temporais entre programação e acidente e, mais a fundo, nos arranjos aspectuais desse último.

A esse propósito, três são as linhas de raciocínio que são relevantes e oportunas desenvolver. Antes de mais nada, pode-se assumir que o acidente seja um acontecimento pontual ao mesmo tempo terminativo e incoativo. Essa leitura justifica-se por duas razões. Em primeiro lugar, pelo fato de que Landowski define o acidente tanto como a ruptura da ordem, isto é, como algo a ela logicamente consequente quanto como o ponto de partida da sintaxe do quadrado 
dos regimes de sentido e interação, ou seja, do percurso de um sujeito que, encontrando-se em um mundo aleatório e caótico, comece a procurar algum destinador para dar um sentido novo à sua existência (LANDOWSKI, 2014, p. 70-71). Em segundo lugar pela denominação dos papeis que o semioticista francês atribui ao acidente. Diferentemente da programação, cujo papel é assimilável ao papel temático da gramática narrativa de Greimas (GREIMAS; COURTÉS, 2008, p. 496), o acidente cumpre, entre outros, dois papeis: um "papel catastrófico" (de algo que rompe com a cadeia sedimenta dos eventos) e um "papel catalítico" (de algo que engendra um novo ciclo, cujas trajetórias são, no momento no qual se manifesta, ainda imprevisíveis) (LANDOWSKI, 2014, p. 79). Trata-se, como veremos em breve, de uma questão relevante para os escopos do presente estudo. Todavia, é preciso reconhecer que Landowski reserva ao papel catastrófico uma posição privilegiada na definição do regime de acidente, enfatizando, assim, o seu aspecto terminativo.

Prosseguindo, parece-me profícuo estabelecer uma correlação entre a valorização aspectual (pontual/terminativa e pontual/incoativa) do acidente e estesia. É o que havia feito Greimas em Da Imperfeição (2002) ao abordar a problemática do acidente estésico, entendido como uma fratura da rotina cotidiana de matriz eminentemente sensível. Ora, é verdade que em As Interações Arriscadas Landowski, diferentemente de Greimas, trata separadamente o sensível e o aleatório, fazendo do primeiro o princípio regulador do regime do ajustamento e do segundo o princípio regulador do regime do acidente (LANDOWSKI, 2014, p. 73). No entanto, quando se analisam os acidentes que marcam o devir dos processos sociopolítico contemporâneos essa distinção faz-se mais opaca e torna-se indispensável considerar seus investimentos estésico-passionais. De resto, é o próprio Landowski que nos convida a seguir essa diretriz ao admitir, nas conclusões de As interações arriscadas, a necessidade de abordar conjuntamente regimes de sentido e interação e regimes passionais, refletindo, entre outras coisas, sobre as "paixões do acaso" (LANDOWSKI, 2014, p. 106).

Seguindo tais indicações, proponho pensar o acidente político como um acontecimento suscetível de desencadear uma cadeia de reações sensíveis nos contextos sociais nos quais se verifica. Aliás, no acidente político, é o sensível em seu estado mais puro a demarcar o processo comunicacional. Todas as primaveras que marcaram a segunda década do século XXI, tanto aquelas do mundo árabe (Tunísia, Egito, Turquia), quanto aquelas do mundo ocidental (o movimento dos indignados na Espanha, as revoltas de Zuccotti Park nos Estados Unidos e, inclusive, as jornadas de junho de 2013 no Brasil) foram caracteri- 
zados, como aponta Butler (2015) por um contato entre corpos que dá lugar a um novo interregno espaço-temporal. É o que Landowski têm chamado de "alastramento", uma propagação de sentido que não corresponde "nem a uma empatia de ordem cognitiva, nem a um contagio viral, mas a uma expansão por contiguidade de elementos que se tocam entre si, à maneira de um incêndio em uma floresta" (LANDOWSKI, 2018, p. 15, tradução nossa) ${ }^{2}$ - típica dos movimentos populistas contemporâneos. Traduzindo, e é o que procurarei demonstrar a partir da análise do caso brasileiro: a força do acidente, bem como a sua duração, é proporcional à carga estésica que o engendra e que ele se torna capaz de mobilizar. Um pouco como acontece, em física, nos sistemas quânticos (ROVELLI, 2017), a intensidade e a extensão temporal do acidente dependem da energia gerada pelo contato entre elementos em movimento que interagem entre si. Isso signifique, talvez, que o acidente não seja apenas um produtor de forças sensíveis, como também, vice-versa, o produto de um encontro de sensibilidade de outra ordem, reconduzível ao regime do ajustamento. Mas, infelizmente, esse é um assunto que ultrapassa os limites desta pesquisa. Fiquemos, então, dentro dos limites previamente traçados.

Por fim, há de se ressaltar a correlação entre acidente e indeterminação semântica, também crucial no conceito lotmaniano de explosão. Vimos antes que Landowski atribui ao acidente um papel catastrófico, que determina um colapso do sistema de crenças e valores em jogo em um determinado horizonte narrativo. O regime de sentido ao qual dá origem esse choque é o "sem sentido", a "insensatez" (LANDOWSKI, 2014, p. 71-80). Infere-se, portanto, que o acidente dá lugar a uma indeterminação semântica de caráter negativo. No entanto, relembrando o que dissemos antes a respeito da possibilidade, admitida pelo próprio Landowski, de postularmos um "papel catalítico" do acidente e de o pensarmos enquanto o momento embrionário de um novo percurso narrativo, as coisas tornam-se mais complexas. O que se tem, nesse caso, não é o não sentido, mas o sentido em excesso, um universo plural e altamente indeterminado de significações possíveis, como no caso das jornadas de junho de 2013: contra o aumento da tarifa "contra a corrupção", "para mais saúde", "para mais educação", "muda Brasil", "para um Brasil melhor", e assim por diante. Ou seja, quando se adentra o mundo sublunar da história social, percebe-se que a cifra semântica do acidente não é apenas o nonsense, a insensatez, mas o sentido demais. Um superávit semântico

2 Do original: Ni empathie d'ordre cognitif ni contagion virale mais expansion par contiguïté des éléments touchés, à la manière d'un incendie de forêt. 
que, conforme sugere o próprio modelo de Landowski, desembocará, mais cedo ou mais tarde, em um regime de manipulação, isto é, em uma disputa entre intencionalidades diversas, cada uma das quais procurará imprimir um rumo à indeterminação semântica proporcionada pelo acidente. E não apenas isso: os dois eixos - acidente/estesia e acidente/indeterminação semântica - possuem, ainda, relações entre si. Quanto mais elevada será a carga estésica em jogo no acidente, mais densa será a nebulosa de significados por ele veiculada. Como veremos em relação ao caso brasileiro, as mídias sociais digitais cumprem, na definição dessa configuração temporal, um papel de primeiro plano.

\section{A explosão: relendo Jurij Lotman}

Em seus últimos escritos, o semioticista Jurij M. Lotman $(1995 ; 2009)$ reflete sobre as articulações entre processos graduais e processos pontuais no devir das culturas. As culturas, diz Lotman, envolvem-se segundo dois movimentos complementares: regularmente, passo após passo, e pontualmente, por saltos. O primeiro movimento é marcado pelo desenvolvimento cíclico da história; o segundo, por transições e acelerações improvisas, que o estudioso define "explosões" (LOTMAN, 1995; 2009).

De difícil demarcação, o conceito de explosão possui, na teoria lotmaniana, duas possíveis acepções. Por um lado, indica os momentos históricos nos quais alguma coisa "interrompe a cadeia das causas e dos efeitos e projeta, na superfície, um espeço de eventos igualmente prováveis, dos quais é impossível dizer, em princípio, qual se realizará" (LOTMAN, 1995, p. 35, tradução nossa)3. Por outro lado, designa um processo de explosão de sentido - de novos significados, metáforas, analogias - que emerge e se configura como o resultado da tradução do que antes se julgava intraduzível. Ou seja, nas palavras do próprio Lotman, a geração de uma série de "combinações semânticas inesperadas, impossíveis ou proibidas em uma fase precedente" (LOTMAN, 1995, p. 93, tradução nossa) ${ }^{4}$.

No primeiro caso, lida-se com a imprevisibilidade de ações, fatos ou eventos. No momento em que George d'Anthès aperta o gatilho de sua arma, afirma Lotman, não apenas a vida e a morte de Puškin são igualmente prováveis, como também existe, potencialmente, uma outra história da Rússia (LOTMAN, 1995,

\footnotetext{
3 Do original: Il momento dell'esplosione interrompe la catena delle cause e degli effetti e proietta in superficie uno spazio di eventi parimenti probabili di cui è impossibile per principio dire quale si realizzerà..

4 Do original: Da questo punto di vista, il nuovo nell'arte può essere caratterizato come la possibilità di combinazioni strutturali semantiche inattese, impossibili o proibite in una fase precedente.
} 
p. 36). Nessa perspectiva, "a explosão de possibilidades diversas insere, no espaço cultural, a casualidade: as possibilidades são todas prováveis" (LOTMAN, 1995, p. 37-38, tradução nossa) ${ }^{5}$. Como explica Lotman, é uma casualidade o fato de que Luís XVI, apaixonado por mecânica, tenha contribuído a projetar a máquina que lhe cortaria a cabeça: a guilhotina. Assim como é um caso o fato de que ela tenha se tornado o símbolo da revolução francesa (se se considerar, por exemplo, que os detalhes técnicos relativos aos assassinatos dos reis em outras revoluções não foram revestidos de valências simbólicas).

No entanto, isso é verdadeiro apenas quando se observa o momento da explosão do presente para o futuro, quando todas as estradas podem ainda ser percorridas. Ao contrário, quando se observa a cadeia dos eventos em direção inversa, do futuro para o passado, atribui-se, ao elemento imprevisível, um significado, uma "motivação adicional retroativa" (LOTMAN, 1995, p. 37, tradução nossa) ${ }^{6}$.

No segundo caso, a explosão é considerada como uma explosão de sentido, isto é, como a emergência de uma série de conexões semânticas não previstas entre valores, temas, figuras, símbolos distantes ou até potencialmente contraditórios. Nas palavras do autor, "o estado da explosão é caracterizado por um momento de equalização de todas as oposições. Aquilo que é diferente parece ser o mesmo. Isso possibilita saltos inesperados rumo a estruturas organizacionais completamente diferentes e imprevisíveis" (LOTMAN, 2009, p. 158, tradução nossa) ${ }^{7}$. É o que acontece nas jornadas de junho de 2013 , nas quais as palavras de ordem iniciais contra o aumento da tarifa do transporte público entram em contato direto com outros motes mais genéricos, formando uma constelação amorfa e indecifrável de significados relativos não apenas ao sentido geral dos protestos, como também ao sentido geral do Brasil.

Como o acidente, a explosão possui, portanto, uma dúplice caraterística aspectual. Por um lado, ela define um acontecimento terminativo, que decreta a ruptura de um sistema sedimentado de relações; pelo outro ela configura-se como um acontecimento incoativo, que abre para novas possíveis reconfigurações. Como observa Sedda (2012), é como se toda explosão implicasse uma implosão que se desenvolve, simultaneamente, no mesmo horizonte espaço-temporal da primeira.

\footnotetext{
5 Do original: L'esplosione di possibilità diverse introduce nello spazio culturale la casualità: le possibilità sono tutte probabili.

6 Do original: L'elemento imprevedibile viene dotato di significato, munito di motivazione aggiuntiva retroattiva.

7 Do original: The state of explosion is characterized by the moment of equalisation of all oppositions. That which is different appears to be the same. This renders possible unexpected leaps into completely different, unpredictable organisational structures.
} 
Assim definido, "o momento da explosão coloca-se na interseção entre passado e futuro, em uma dimensão quase atemporal" (LOTMAN, 1995, p. 35, tradução nossa) $)^{8}$. Como se fosse vivido "fora do tempo, ainda que, na realidade, possa estender-se ao longo de um amplo espaço temporal" (LOTMAN, 2009, p. 158, tradução nossa) ${ }^{9}$. Uma dimensão atemporal que se delineia enquanto tal justamente pelo fato de ser marcada por um elevado grau de indeterminação semântica, como na releitura do conceito landowskiano de acidente que propus na seção anterior.

No entanto, ao cotejar acidente e explosão é preciso ressaltar ao menos três possíveis diferenças:

f) enquanto para Landowski a indeterminação é predominantemente negativa, para Lotman é positiva: o acento é posto, nesse caso, no superávit de sentido ao qual a explosão dá lugar, cujas trajetórias podem se espalhar nos cantos mais recônditos do espaço cultural, convergindo e divergindo de diferentes maneiras (LOTMAN, 2009, p. 172);

g) se Landowski não se exprime explicitamente em relação à duração do acidente, para Lotman não há coincidência entre processos graduais e longa duração, de um lado, e processos explosivos e curta duração do outro. Como ele mesmo adverte, "a ideia de atemporalidade não está vinculada à real cronologia do processo, que na realidade pode durar por muito tempo" (LOTMAN, 1995, p. 35 , tradução nossa) $)^{10}$. Por exemplo, a queda do Império Romano e os abalos causados na sociedade russa pela Primeira Guerra Mundial, continua o semioticista, são, apesar de ter se protraído por muitos anos, típicos processos explosivos (LOTMAN, 1995, p. 35-38);

h) contrariamente a Landowski, que vislumbra a sua necessidade, é ausente, em Lotman a problemática da estesia e dos impactos sensíveis e passionais da explosão, cuja problematização é, a meu ver, imprescindível para entendermos as dimensões temporais dos processos sociopolíticos e midiáticos contemporâneos.

Complementando-se reciprocamente, as categorias de Landowski e Lotman nos oferecem a possibilidade de repensarmos a dinâmica dos processos políticos e mediáticos no Brasil contemporâneo, bem como as relações e o papel das novas e das velhas mídias na construção e na organização da temporalidade social. Em particular, nos permitem postular a possibilidade de uma ruptura prolongada, de um acidente, segundo a terminologia de Landowski, ou de uma explosão,

8 Do original: Il momento dell'esplosione si colloca nell'intersezione di passato e futuro, in una dimensione quasi atemporale.

9 Do original: This moment is experienced out of time, even if, in reality, it stretches across a very wide temporal space.

10 Do original: L'idea di temporalità non è legata alla reale cronologia del processo, che nella realtà può durare anche molto a lungo. 
segundo aquela de Lotman, caracterizada por um alto grau de indeterminação semântica e por um elevado nível de carga estésica.

\title{
De junho de 2013 ao impeachment de Dilma Rousseff
}

Como antecipei na Introdução, os protestos de 2013 são marcados, tanto nas ruas quanto nas redes, por uma reviravolta semântica repentina"1. As primeiras manifestações (3, 6, 11 de junho de 2013) são protagonizadas por palavras de ordem e hashtags claras e focadas: "três reais é roubo", "por uma vida sem catracas", "se a tarifa não baixar a cidade vai parar". No entanto, em 13 de junho, após a repressão, em São Paulo, do quarto grande ato contra a tarifa por parte da polícia militar (SINGER, 2018), o cenário muda: os slogans precisos de antes cedem lugar a motes com significados abertos e confusos. Como mostra a plotagem realizada por Fabio Malini, verifica-se, naquele dia, nas redes sociais, a explosão de "uma multiplicidade de hashtags: \#passelivre; \#contraoaumento; \#vemprarua; \#changebrazil; \#tarifazero; \#indignação; \#occupySP; \#protestoSP; \#13jSP. Diferentes movimentos dentro do movimento" (MALINI, [2013]). A estes, somam-se outros lemas: "Não é pelos vinte centavos", "Verás que um filho teu não foge à luta", "O gigante acordou", "Change Brazil", de cunho implicitamente ou explicitamente nacionalista.

Em seu estudo, Malini reconstrói a rede de retweets que protagonizou a tarde do dia 13 de junho, identificando quais perfis e postagens alcançaram maior centralidade, isto é, quais conseguiram estabelecer o maior número de nós. Como argumenta o autor, um dos dados mais instigantes que emergem da análise é:

\begin{abstract}
A emergência de perfis que não possuem grande popularidade na internet (chamados nós pobres), mas com capacidade de afirmar algo que se espalha na rede [...]. @LeoRossatto é um caso desse tipo, ao publicar "A tarifa virou a menor das questões agora. Os próximos protestos precisam ser, antes de tudo, pela liberdade de protestar", viu sua mensagem ganhar ares de slogan [...] O mesmo caso ocorreu com @choracuica, que publicou (sendo retuitada 190 vezes): "não é mais sobre a tarifa. Foda-se a tarifa. Isso ficou muito maior que a questão da tarifa". E também com a mensagem de @gaiapassarelli:
\end{abstract}

\footnotetext{
"Em textos anteriores analisei, a partir de um corpus mais extenso, a dinâmica das interações sociossemióticas que regeu o processo político-mediático que levou das jornadas de junho de 2013 ao impeachment de Dilma Rousseff. Limito-me aqui a uma reconstrução mais resumida, orientada para os escopos específicos do presente artigo, que servirá como ponto de partida para testar, na próxima seção, as hipóteses elencadas na Introdução.
} 
"há algo grande acontecendo e é menos sobre aumento de tarifa e mais sobre tomar posição. Todo mundo deveria prestar atenção". E ainda com @tavasconcellos: “RT @tavasconcellos: não é mais uma discussão sobre tarifa, transporte, baderna, sobre nada disso. É sobre o direito de se manifestar por qualquer causa". Essas quatro mensagens, somadas, são as que mais obtiveram republicação no Twitter (quase mil republicações) (MALINI, [2013]).

Em outro artigo, Malini traça a "explosão" - é esse o termo utilizado pelo autor (MALINI, 2016, p. 11) - da hashtag \#vemprarua entre a tarde do dia 15 e a noite do dia 17 de junho, quando acontecem os atos mais participado de todas as jornadas (BBC, 2013). Agitada inicialmente por perfis ativistas, em seguida por perfis associados a organizações sociais e, enfim, por celebridades e humoristas, a hashtag espalha-se pela rede, conforme resume o gráfico abaixo elaborado pelo próprio Malini ([2013]).

Figura 2 - A explosão de Retweets com a hashtag \#vemprarua entre a tarde do dia 15 à noite do 17 de junho de 2013

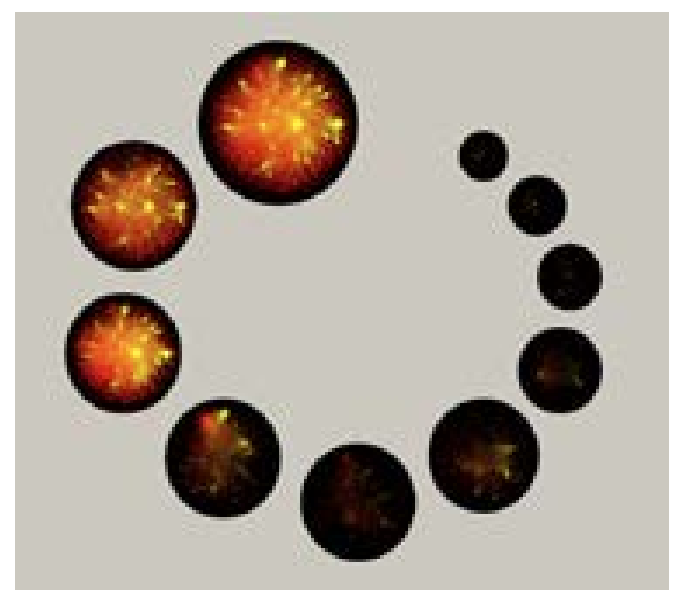

Fonte: Fabio Malini ([2013]) $)^{12}$

Malini está interessado em discutir os elos entre as diferentes temporalidades através das quais se difundiu a hashtag \#vemprarua e o engajamento, em cada etapa, de atores diversos, bem como as relações de poder e os conflitos que se estabelecem entre eles (MALINI, 2016, p. 11-13). No entanto, o aspecto que gostaria de ressaltar é outro: a explosão da hashtag \#vemprarua e dos outros slogans que circulam naqueles dias define-se, em todas as suas fases e indepen-

12 Disponível em: http://www.labic.net/cartografia-das-controversias/a-batalha-do-vinagre-por-que-o-protestosp-nao-teve-uma-mas-muitas-hashtags/. Acesso em: 26 set. 2018. 
dentemente dos atores envolvidos, por um traço distintivo: a indeterminação semântica. Em suma: a explosão é uma explosão de vagueza.

Das ruas e das redes, a vagueza migra para a esfera da grande mídia. A cobertura dos protestos de jornais, rádio e televisão engrossa a nebulosa de conteúdo que os envolve, reforçando a ideia de que os manifestantes desceram às ruas não contra algo preciso - o aumento da tarifa - mas "contra tudo": "Milhares vão às ruas contra tudo", é o título da capa da Folha de S. Paulo publicada no 18 de junho de 2013, no dia seguinte, enquanto o do caderno "Cotidiano" é, simplesmente, "Contra". Na mesma linha, na manhã do dia 17, ao vivo na $C B N$, o comentarista Arnaldo Jabor, que havia definido os manifestantes de vândalos e baderneiros, admite ter se enganado. Os jovens que ocupam as ruas não são um "bando de irresponsáveis movidos por um anarquismo inútil [mas] uma formação política original, justamente pelo fato de não ter um rumo, um objetivo certo a priori" (JABOR, [2013]).

Duas narrativas começam a ganhar corpo: a primeira é aquela de um país em crise, onde nada funciona; a segunda é a narrativa de um Brasil unido na indignação. Conforme conta essa última, quem manifesta naqueles dias não é apenas uma fatia restrita e minoritária da população (o MBL, os jovens contrários ao aumento da tarifa etc.), mas a totalidade do povo brasileiro interagindo ao uníssono em um aqui e agora ao mesmo tempo físico e mediático.

No dia 18 de junho o jornal O Globo titula: "O Brasil nas ruas". Em 19 de junho, na partida inaugural da Copa das Confederações, Brasil-México, em Fortaleza, o estádio inteiro levanta para cantar o hino nacional à capela. Ao vivo, a câmera da TV Globo enquadra torcedores que seguram cartazes com as seguintes palavras: "Esse protesto não é contra a seleção, mas sim contra a corrupção! \#ogiganteacordou". Em 20 de junho de 2013, a Rede Globo interrompe as novelas Flor do Caribe e Sangue Bom para deixar espaço às imagens dos protestos. O Jornal Nacional do mesmo dia vai ao ar sem edição, já que, como afirmou na abertura o editor William Bonner, "Não faz sentido exibir uma edição do Jornal Nacional, já que os fatos estão sucedendo ao sabor do momento..." (UOL, 2013). Na edição do dia 24 de junho, o Estado de S. Paulo dá destaque, na capa, a uma imagem dos tons verde-amarelos, em que os manifestantes, em primeiro plano, erguem a bandeira nacional. Em 26 de junho, a Revista Veja vai às bancas com uma "edição histórica" sobre as manifestações. A foto de capa retrai uma jovem mulher de costas, cingida pela bandeira com, ao fundo, uma barricada em chamas. Logo abaixo, o título: "Os sete dias que mudaram o Brasil". No mesmo dia, o cantor e compositor Gabriel Moura lança em sua página de YouTube o vídeo de Chega 
(não é pelos vinte centavos) ( $\mathrm{G} 1,2013)$, cujos versos deixam ainda mais claro que o protagonista dos protestos é o povo brasileiro, cansado, por assim dizer, de tudo o que está aí: "Chega de impunidade. Chega de desigualdade. Chega. Todo mundo está enxergando. Não é pelos vinte centavos que estamos lutando".

Dois são, portanto, os traços distintivos que diferenciam o discurso das jornadas de junho de 2013: um elevado grau de indeterminação semântica e um elevado grau de carga estésica, de alastramento de forças sensíveis, conforme a acepção que Landowski (2018, p. 15) confere ao termo. Surgidas nas redes sociais, ambas se espalham rapidamente em outras esferas discursivas, ocupando telas de televisores, páginas de revista e jornais impressos e digitais, e frequências radiofônicas.

Aos poucos, o discurso midiático-político deixa de canalizar tanto a vagueza quanto a estesia em um todo indistinto para direcioná-la contra alguém específico: a ex-presidente Dilma Rousseff e o seu governo, Luís Inácio Lula da Silva e o Partido dos Trabalhadores (PT).

Durante as jornadas de junho de 2013 percebem-se os primeiros sinais de tal redirecionamento. Em ocasião da abertura da Copa das Confederações, a ex-presidente é vaiada pelos espectadores do estádio Mané Garrincha de Brasília (ALENCASTRO, 2013). O evento se repete um ano mais tarde, em junho de 2014, na partida de abertura da Copa do mundo de 2014. Após mais um hino nacional cantado à capela, grupos de torcedores dirigiram xingamentos rumo à então presidente do País (G1, 2014).

Em 15 de março de 2015, o Movimento Brasil Livre e o Movimento Vem Pra Rua, surgidos no final de 2014 em apoio à Operação Lava Jato, chamam uma manifestação contra o governo Dilma. Milhares de pessoas, vestidas de verde e amarelo e com camisas da seleção brasileira, tomam às ruas em diversas cidades do Brasil, pedindo o impeachment da presidente.

No dia seguinte, o jornal $O$ Globo titula: "O Brasil vai às ruas contra Dilma e Lula e a favor de Moro". Mais uma vez, ganha corpo a narrativa de que o protagonista dos protestos é o Brasil, e o antissujeito é encarnado pelas figuras de Dilma e Lula. Ou melhor, constrói-se a imagem de uma disputa entre brasileiros (o "povo" verde-amarelo pró-impeachment) e não brasileiros (Dilma, Lula e seus aliados): "Aliados de Dilma fazem manifestação em todos os estados", é a capa de $O$ Globo do dia 19 de março de 2015, dias seguintes aos atos a favor da permanência, em seu cargo, da chefe do Governo.

Tal redirecionamento não se dá apenas no plano da semântica, como também naquele da sintaxe interacional. Ao passo que o antissujeito vem sendo 
reconhecido e apontado sob o perfil da linguagem verbal e da linguagem visual, é acionado um desvio: a carga estésica das jornadas de junho de 2013 é canalizada contra Dilma. Um exemplo disso são os panelaços que, a partir das manifestações de março de março de 2015 tornam-se cada vez mais frequentes, sendo impulsionados pela mídia tradicional, em particular pelo Jornal Nacional, o qual constrói uma série de debreagens e embreagens enunciativas (GREIMAS; COURTÉS, 2008) através dos quais a cidade projeta-se na TV e a TV projeta-se na cidade. Uma correlação íntima e profunda entre mídia e sociedade, entre a mídia e a vida real, que resulta em um novo acordo estésico. Não se trata apenas de um espelhamento recíproco, mas de uma vivência coletiva em ato (FECHINE, 2008), da experiência de um sentir compartilhado.

No entanto, enquanto a identidade diferencial do Brasil vem sendo aos poucos especificada, a sua definição positiva continua obscura. Pense-se, a este propósito, na campanha lançada pela Revista Veja em 14 de abril de 2016, às vésperas do pleito na Câmara dos Deputados. Uma serie de cartazes é divulgada nas bancas e no site da revista. Sob um fundo amarelo, alternam-se as seguintes sentenças: "Veja só vê um lado: o lado do Brasil"; Veja persegue. Persegue a verdade"; "Quero um Brasil melhor, Já"; "Chega de corrupção"; "Veja é comprometida. Comprometida com a democracia". A própria votação na Câmara dos Deputados é outro exemplo emblemático da repercussão da não especificação dos traços distintivos e dos programas narrativos do Brasil anti-Dilma. Nenhum dos 367 deputados que votaram "sim" mencionou a real acusação contra a presidente. Envolvida em bandeiras do Brasil, entoando versos do hino-nacional, a maioria votou em nome de causas diversas e abstratas, que não tinham relação direta com as razões do processo: em nome de Deus, do povo, da família brasileira.

\section{História, política e mídia: temporalidades cruzadas}

Em diversos trechos de $O$ lulismo em crise, André Singer (2018) descreve as jornadas de junho de 2013 como um momento de ruptura e/ou de inflexão na trajetória do lulismo. Vários são os termos e as metáforas utilizadas pelo sociólogo. No entanto, todas remetem à ideia de um abalo. Como afirma na "Introdução" "junho representou [...] um corte no período de cinco anos e meio que Dilma governou o Brasil (SINGER, 2018, p. 29), após o qual abriu-se "uma avenida para o antilulismo" (SINGER, 2018, p. 31). Na primeira página do terceiro capítulo, intitulado "A encruzilhada de junho", os protestos são definidos como uns "acontecimentos inesperados [que] dividem o período de Dilma em dois. Até lá, 
a presidente gozava de aprovação nas pesquisas, e o lulismo estava vitaminado pelo sucesso nas eleições de 2012. Depois das manifestações, a presidente cai de 57\% de bom e ótimo para 30\%" (SINGER, 2018, p. 99). Três páginas depois, junho é descrito como um "tremor" (SINGER, 2018, p. 102). Na conclusão, repete-se a dose: "junho somou insatisfações diferentes e funcionou como o apito de pressão sobre o lulismo" (SINGER, 2018, p. 291), após o qual a ex-presidente foi sendo arrastada por um vendaval de forças que culminou no seu impeachment e o lulismo "despedaçado" (SINGER, 2018, p. 297).

Ne mesma diretriz, outros autores descrevem as jornadas como um "choque de democracia" (NOBRE, 2013) ou como uma "pancada que atingiu o cerne do discurso do governo federal, que balançou na hora, de forma apalermada, sem saber como reagir" (BUCCl, 2016, p. 16). A partir daí, houve uma guinada de opinião em relação ao estado de saúde de Pais. Como afirma Schwarz (2013, p. 3):

\footnotetext{
Em duas semanas o Brasil que diziam que havia dado certo - que derrubou a inflação, incluiu os excluídos, está acabando com a pobreza extrema e é um exemplo internacional - foi substituído por outro país, em que o transporte popular, a educação e a saúde públicas são um desastre [...].
}

Levando às extremas consequências tais raciocínios, e com base na releitura dos conceitos de acidente (LANDOWSKI, 2014) e explosão (LOTMAN, 1995; 2009) antes desenvolvida, proponho considerar as jornadas de junho de 2013 como um acontecimento disruptivo que catapulta a sociedade e a política brasileira em uma fase histórica imprevisível, a qual se estende até o impeachment de Dilma Rousseff e, pode-se supor, até às eleições presidenciais de 2018, embora, como disse, a análise desta segunda fase ultrapasse as fronteiras deste artigo.

Dito isso, é importante mostrar como tal processo acidental/explosivo se articula. É essa, pois, a maior contribuição que a perspectiva sociosemiótica pode oferecer tanto ao campo das Ciências Sociais, quanto àquele dos estudos comunicacionais.

Antes de tudo, é preciso destacar que as jornadas de junho de 2013 engendram dois movimentos que se entrelaçam reciprocamente entre si em um único continuum espaço-temporal: um movimento implosivo e um movimento explosivo (SEDDA, 2012). O primeiro diz respeito ao colapso do velho, isto é, ao fragmentar-se do sistema de valores e crenças da era Lula: a ideia, como vimos, de um país emergente, de um sistema político e econômico aparentemente estável etc. (NOBRE, 2013; SINGER, 2018; SCHWART, 2013); o segundo à insurgência do 
novo, cujas formas e cujas trajetórias semânticas permanecem indeterminadas, tanto no que diz respeito à sua definição negativa ("contra tudo", para relembrar o título da Folha de S. Paulo de 18 de junho de 2013), quanto no que concerne à sua definição positiva ("Muda Brasil", "Por um Brasil melhor" etc.).

Ora, reinterpretando semioticamente os dados e a análise de Malini ([2013]; 2016), parece-me possível afirmar que o que produz esse movimento implosivo/ explosivo de sentido é a cadeia de interações promovidas nas e pelas redes sociais. Isso, principalmente, no que diz respeito à explosão propriamente dita, ou seja, à insurgência e a proliferação de novos significados, sejam positivos, sejam negativos. É nelas e através delas que, a partir do dia 13 de junho de 2013, se consolida a ideia de que os protestos não são apenas pelos vinte centavos, mas por algo muito maior, cuja essência permanece obscura. Vivencia-se aí, como na explosão lotmaniana, uma equalização das oposições e um achatamento do espaço semântico da política brasileira. Tudo entra em conexão com tudo: o transporte com a saúde, a corrupção com os vinte centavos, a Copa das Confederações e as obras para a Copa do Mundo com a PEC 37 e assim por diante, sem que haja, no entanto, um arranjo e um direcionamento específicos.

Outro dado a ser evidenciado é que esta proliferação de sentido se configura como um fenômeno de ordem sensível. De modo parecido com o que postula Landowski em relação aos fenômenos de alastramento dos hodiernos movimentos populistas, as interações em e na rede engendram uma corrente que "eletriza" (LANDOWSKI, 2018, p. 14-15, tradução nossa) a comunidade de usuários, transitando rizomaticamente de um corpo para o outro. A prova disso é a explosão da hashtag \#vemprarua (MALINI, 2016), que se traduz em uma participação numericamente relevante nos protestos de rua de 17 de junho e dos dias seguintes (SINGER, 2018). Protestos, como vimos, cuja cifra reside no contágio, corpo a corpo, entre os manifestantes diante do hino e da bandeira nacional. Em suma, entre redes e ruas não há solução de continuidade: a carga estésica que percorre tanto a primeira quanto as segundas é a mesma.

Emerge, neste momento, um tempo novo. A eclosão de significações e a ebulição dos afetos dá origem a um presente atemporal amorfo e imprevisível, dominado pela experiência eletrizante do aqui e agora, pelas pulsões do imediatismo e pelo imediatismo das pulsões do corpo social. Naquelas semanas, tudo parece acontecer ao vivo, tudo parece não ter nem início nem fim, ou, vice-versa, tudo parece terminar e recomeçar sem parar (os protestos e, ao mesmo tempo, as narrativas sobre os protestos). Não há espaço para determinações precisas. O que prevalece é a experiência estésico-estética do momento e no momento, a 
vivência, em ato, do espetáculo do presente, compartilhado, ao mesmo tempo, nas ruas e nas redes. Tal percepção torna-se ainda mais tangível quando essa temporalidade nebulosa e estesicamente intensa começa a ser promovida pela mídia tradicional, em particular aquela televisa, cuja programação passa a ser interrompida para mostrar, sem edição, as manifestações (UOL, 2013).

Tem-se aqui uma correspondência entre a visão lotmaniana de "tempo atemporal" (LOTMAN, 1995; 2009), e outras visões da temporalidade oriundas dos estudos comunicacionais, como aquela de Manuel Castells sobre o "tempo intemporal", que caracteriza o paradigma informacional da sociedade em rede. Segundo as palavras do autor, o tempo intemporal:

Ocorre quando as características de um dado contexto, ou seja, o paradigma informacional e a sociedade em rede, causam confusão sistêmica na ordem sequencial dos fenômenos sucedidos naquele contexto. Essa confusão pode tomar a forma de compressão da ocorrência dos fenômenos, visando à instantaneidade, ou então de introdução de descontinuidade aleatória da sequência. A eliminação da sequência cria tempo não-diferenciado, o que equivale à eternidade (CASTELLS, 2005, p. 556).

É a confusão na ordem sequencial dos fenômenos, típica da sociedade em rede que, em junho de 2013, produz a compressão do fluxo temporal, introduzindo a descontinuidade aleatória e a instantaneidade no curso histórico da vida política nacional, conforme vimos em Landowski (2014) e Lotman (1995; 2009). No entanto, o que a evolução das jornadas mostra é que essa confusão não é apenas sistêmica e, como parece deixar a entender Castells, de ordem cognitiva. Longe disso, o caos é sensível, corpóreo, intersomático. As redes são redes de afetos e paixões - e isso interfere não apenas na construção do tempo midiático, como também do tempo social (BARBOSA, 2017). Em outros termos, a carga estésica torna-se uma variável fundamental para entendermos as manifestações do presente atemporal na sociedade do século XXI.

E não apenas isso. A reconstrução da trajetória que conduz, em agosto de 2016, ao impeachment de Dilma Rousseff aponta para outro aspecto relevante: a temporalidade amorfa, comprimida e instantaneísta não acaba com o dissipar-se das jornadas. O discurso político-mediático pós-junho de 2013 estende, ao longo dos anos sucessivos, o regime temporal surgido naquele mês. De que maneira? Fortalecendo tanto a indeterminação semântica quanto a carga estésica que marcaram as jornadas. 
Contudo, o alastramento de vagueza e sensibilidades acontece de modo diferente. Enquanto a identidade positiva do novo Brasil continua não sendo precisada, a sua identidade negativa torna-se mais clara: Dilma, Lula e seus aliados, para retomarmos o título de O Globo no dia 19 de março de 2015, são apontados como antissujeitos da nação. Neles é canalizada a indignação geral de junho, que se transforma, agora, em paixões mais precisas - raiva, repulsa etc. - contra alguém.

Como vimos, o discurso jornalístico da mídia tradicional (Globo, Folha de $S$. Paulo, Estado de S. Paulo, Revista Veja), cumpre, nesse processo, um papel relevante. São a indeterminação semântica e o envolvimento estésico-passional por ele promovidos que dilatam a explosão de junho de 2013 e projetam para frente a sua temporalidade, extinguindo as distinções entre passado, presente e futuro.

Pode-se dizer, portanto, conforme sugere Lotman (1995; 2009), que o intervalo temporal que se desdobra entre 2013 e 2016 representa um processo explosivo duradouro, marcado por um presente atemporal dilatado ou, para dizê-lo com Castells (2005, p. 556), por um presente intemporal que, em um determinado nível, constitui um tempo não diferenciado.

Digo em um determinado nível porque, observando mais a fundo a reconstrução acima conduzida, percebe-se que a trajetória que ata as jornadas de junho e o impeachment de Dilma é marcada por uma sucessão serializada de eventos político-mediáticos pontuais e de grande impacto estésico: manifestações, panelaços, vazamentos (CARVALHO; BRUCK, 2017), votações na Câmara, no Senado etc., narrados e vividos, nas ruas e na mídia, nos moldes de uma disputa sensível entre torcidas futebolísticas. Em outros termos, o discurso político-midiático constrói e articula o tempo da crise política brasileira nos moldes de uma ficção seriada televisiva, na qual tudo acaba e recomeça de modo constante, contribuindo a engrossar as tensões da sociedade e a canalizá-las dentro de seu âmbito específico. Se temos, portanto, em um nível, a percepção de um fluxo temporal contínuo, durativo, atemporal, relativo a um único acontecimento que se delonga entre junho de 2013 e agosto de 2016, em outro nível esse mesmo fluxo aparece como descontínuo, marcado por uma iteratividade perpétua de acontecimentos estésicos em relação entre si, por uma série de microexplosões dentro da macroexplosão geral. Entretanto, as duas lógicas não se opõem uma à outra. Pelo contrário, elas definem duas camadas distintas de um mesmo regime temporal: um regime que, parafraseando o historiador francês François Hartog (2015, p. XV), proponho de chamar hiperpresentista. 


\section{Fechamentos e aberturas}

Na reedição norte-americana de Regimes d'historicité, à luz da crise econômica mundial engendrada pelo colapso da empresa Lehman Brothers em 2008, Hartog (2015) redefine o presentismo como "a sensação de que apenas o presente existe, um presente caracterizado, ao mesmo tempo, pela tirania do instante e pela esteira de um presente sem fim" (HARTOG, 2015, p. XV, tradução nossa) ${ }^{13}$. Neste regime de historicidade, típico de nossa época, as distinções entre presente, passado e futuro esvaecem, favorecendo a emergência de "um tempo desorientado, marcado por um certo grau de incerteza" (HARTOG, 2015, p. 196, tradução nossa) ${ }^{14}$.

Como vimos, os acidentes (LANDOWSKI, 2014) e as explosões (LOTMAN, 1995; 2009) que quebram o curso regular da história instauram uma temporalidade próxima àquela descrita por Hartog, um presente atemporal imprevisível e potencialmente duradouro.

A análise da temporalidade da explosão que levou das jornadas de junho de 2013 ao impeachment de Dilma Rousseff aponta para uma intensificação desse processo: vivencia-se, ali, uma exasperação paroxística da temporalidade presentista, um verdadeiro regime hiperpresentista. Seus traços distintivos são a instantaneização, a compressão e a aceleração do tempo histórico-social.

De modo parecido a quanto aponta Barbosa em sua reflexão sobre as correlações entre tempo histórico e midiático, a insurgência e a sedimentação, entre 2013 e 2016, do hiperpresentismo deve-se ao fato de que, "na confluência dos meios digitais o tempo perde sua espessura para se transformar em tempo de fluxo. Constrói-se um presente estendido, no qual eventos se atualizam sem cessar e numa velocidade que ultrapassa os limites passíveis de medição" (BAROBOSA, 2017, p. 19). Ou seja, sobredeterminando aquelas do discurso midiático tradicional e do discurso político, as redes instituem um paradigma temporal hegemônico.

Entretanto, é preciso destrinchar mais a fundo e dizer não apenas o que é o hiperpresentismo, mas como ele se dá, isto é, quais são as suas condições de possibilidade. Neste sentido, a perspectiva sociossemiótica aqui adotada e, em particular, a releitura dos conceitos de acidente de Landowski e de explosão de Lotman revela-se teórica e metodologicamente proveitosa. Em particular, ela nos mostra que o hiperpresentismo político-mediático engendrado pelos acidentes e

13 Do original: The sense that only the present exists, a present characterized at once by the tyranny of the instant and by the treadmill of an unending now.

14 Do original: There emerged a disoriented time, marked by greater uncertainty. 
pelas explosões de sentido que os acompanham - conforme a segunda acepção do conceito lotmaniano antes evidenciada - é ao mesmo tempo a causa e o efeito de:

i) uma articulação profunda entre descontinuidade e continuidade. Se, por um lado, ao olhar a explosão do futuro para o passado pode-se distinguir uma série de recorrências que a definem como um único processo contínuo, pelo outro ela aparece formada por uma cadeia de eventos pontuais que se entrelaçam reciprocamente, compondo, assim o seu sentido global: em outros termos, a continuidade do hiperpresentismo é descontinua, iterativa, fractal;

j) um alto grau de indeterminação semântica, através da qual se consolida tanto a imprevisibilidade quanto a necessidade de resolvê-la, seja apenas negativamente;

k) um alto grau de carga estésica, ou seja, de energias que favorecem o alastramento - via ruas, redes, mídia em geral - de afetos e paixões no corpo social.

Talvez - em alguma instância - o tempo da política na sociedade em rede do século XXI seja isso: a indeterminação e a emoção do tempo.

\section{Referências}

ALENCASTRO, Catarina. Dilma é vaiada na abertura da Copa das Confederações. 0 Globo, Rio de Janeiro, 15 jun. de 2013. Disponível em: https://oglobo.globo.com/brasil/ dilma-vaiada-na-abertura-da-copa-das-confederacoes-8701173. Acesso em: 27 set. 2018. https://doi.org/10.5585/rdb.v3i2.33

BARBOSA, Marialva Carlos. Tempo, tempo histórico e tempo midiático. In: MUSSE, Christina Ferraz; VARGAS, Herom; Nicolau, Marcos (org.). Comunicação, Mídias e Temporalidades. Salvador: EDUFBA, 2017, p. 19-36.

BBC Brasil. BRASIL vive noite de protestos. 17 jun. 2013. Disponível em: http://www.bbc. com/portuguese/noticias/130617 protestos live.shtml. Acesso em: 12 dez. 2017.

BUCCl, Eugênio. Forma bruta dos protestos. São Paulo: Companhia das Letras, 2016.

BUTLER, Judith. Notes toward a Performative Theory of Assembly. Cambridge: Harvard University Press, 2015.

CARVALHO, Carlos A.; BRUCK, Mohazir S. Vazamentos como acontecimento jornalístico: notas sobre performatividade mediática de atores sociais. Revista Famecos, Porto Alegre, v. 25, n. 3, p. 1-20, setembro, outubro, novembro e dezembro, 2018: ID29713. DOI: http:// dx.doi.org/10.15448/1980-3729.2018.3.29713.

CASTELLS, Manuel. A sociedade em rede. Tradução de Roneide Venâncio Majer. São Paulo: Paz e Terra, 2005.

FECHINE, Yvana. Televisão e presença. São Paulo: Estação das Letras e Cores, 2008. 
G1. Seu Jorge canta música sobre manifestações no Brasil, 26 jun. 2013. Disponível em: http://g1.globo.com/musica/noticia/2013/06/seu-jorge-canta-musica-sobre-manifestacoes-no-brasil.html. Acesso em: 24 fev. 2018. https://doi.org/10.5380/mp.v5i2.32317

G1. Dilma é hostilizada durante abertura de Copa do Mundo em São Paulo. 12 jun. 2014. Disponível em: http://g1.globo.com/sao-paulo/noticia/2014/06/dilma-e-hostilizada-durante-abertura-da-copa-do-mundo-em-sao-paulo.html. Acesso em: 24 fev. 2018. https:// doi.org/10.11606/d.16.2009.tde-22032010-163041

GREIMAS, Algirdas J. Da imperfeição. Tradução de Ana Claudia de Oliveira. São Paulo: Hacker Editores, 2002

GREIMAS, Algirdas J.; COURTÉS, Joseph. Dicionário de Semiótica. Tradução de Alceu Dias Lima e outros. São Paulo: Contexto, 2008.

HARTOG, François. Regime of Historicity: presence and experience of time. Tradução de Saskia Brown. New York: Columbia University Press, 2015.

LANDOWSKI, Eric. Interações Arriscadas. Tradução de Luisa Helena Oliveira da Silva. São Paulo: Estação das Letras e Cores, 2014.

LANDOWSKI, Eric. Populisme et esthesie. Presentation. Actes sémiotique. Limoges, $\mathrm{n}$. 12, p. 1-19, 2018. Disponível em: http://epublications.unilim.fr/revues/as/6021. Acesso em: 27 set. 2018.

LOTMAN, Jurij M. Cercare la strada. Tradução de Nicoletta Marcialis. Modelli della cultura. Venezia: Marsilio: 1995.

LOTMAN, Jurij M. Culture and Expolosion. Tradução de Wilma Clark. Berlin-New York: De Gruyter Mouton, 2009.

MALINI, Fabio. A Batalha do Vinagre: por que o \#protestoSP não teve uma, mas muitas hashtags. 14 jun. 2013. Disponível em: http://www.labic.net/cartografia-das-controversias/a-batalha-do-vinagre-por-que-o-protestosp-nao-teve-uma-mas-muitas-hashtags/. Acesso em: 26 set. 2018. https://doi.org/10.3726/978-3-653-03610-7/9

MALINI, Fabio. Um método perspectivista de análise de redes sociais: cartografando topologias e temporalidade em rede. XXV ENCONTRO ANUAL DA COMPÓS. Anais... Goiânia: Universidade Federal de Goiás, 2016.

NOBRE, Marcos. Choque de democracia: razões da revolta. São Paulo: Companhia das Letras, 2013.

JABOR, Arnaldo. Amigos, eu errei. É muito mais do que 20 centavos. CBN, 17 jun. 2013. Seção comentaristas. Disponível em: <http://cbn.globoradio.globo.com/default.htm?url=/ comentaristas/arnaldo-jabor/2013/06/17/AMIGOS-EU-ERREI-E-MUITO-MAIS-DO-QUE20-CENTAVOS.htm> Acesso em: 19 dez. 2017. https://doi.org/10.14195/0874-6168 6.7-1 2 
ROVELLI, Carlo. L'ordine del tempo. Milano: Adelphi, 2017.

SCHWARZ, Roberto. Sobre Cidades rebeldes. In: ROLNIK, Raquel et al. Cidades rebeldes: passe livre e as manifestações que tomaram as ruas do Brasil. São Paulo: Boitempo, 2013. https://doi.org/10.11606/d.8.2017.tde-19012017-132254

SEDDA, Franciscu. Imperfette traduzioni. Roma: Nuova Cultura, 2012.

SINGER, André. O lulismo em crise: um quebra cabeça do periodo Dilma (2011-2016). São Paulo: Companhia das letras, 2018. https://doi.org/10.30612/el.v10i19.10074

SOUZA, Jessé. A radiografia do golpe. São Paulo: Leya, 2016.

UOL. Globo interrompe transmissão de novelas, e "JN" não tem edição para acompanhar protestos. 20 jun. 2013. Disponível em: https://televisao.uol.com.br/noticias/ redacao/2013/06/20/globo-interrompe-transmissao-de-novelas-e-jn-nao-tera-edicao-para-acompanhar-protestos.htm. Acesso em: 19 dez. 2017. https://doi.org/10.12702/ dc-000000001

\section{Dados do autor:}

\section{Paolo Demuru - paolodemuru@gmail.com}

Professor Titular do Programa de Pós-Graduação em Comunicação da Universidade Paulista. Pós-Doutor em Comunicação e Semiótica pela Pontifícia Universidade Católica de São Paulo e em Comunicação pela Universidade Federal de Pernambuco. Doutor em Semiótica pela Universidade de Bologna e doutor em Semiótica e Linguística Geral pela Universidade de São Paulo. Autor do livro Essere in gioco. Calcio e cultura tra Brasile e Itália (Bononia University Press, 2014) e de diversas publicações científicas internacionais, atua principalmente nas seguintes áreas: semiótica e estudos da linguagem, teoria da comunicação, estudos culturais e história da cultura, privilegiando análises relativas à comunicação política, à cidade e à construção das identidades sociais e culturais via esporte. Membro da Associazione Italiana di Studi Semiotici e do Laboratorio Romano de Semiotica, graduou-se em Scienze della Comunicazione pela Universidade de Roma "La Sapienza", com estagio de pesquisa realizado no Centro de Pesquisa Sociossemióticas da PUC de São Paulo, do qual é ainda pesquisador ativo.

Endereço do autor:

Programa de Pós-Graduação em Comunicação da Universidade Paulista - Rua Doutor Bacelar, 1212 - Vila Clementino, São Paulo (SP), Brasil 